\title{
Influence of an active T-foil on motions and passenger comfort of a large high-speed wave-piercing catamaran based on sea trials
}

\author{
Chun-Yu Lau ${ }^{1}$ (D) Jason Ali-Lavroff ${ }^{1} \cdot$ Damien S. Holloway $^{1} \cdot$ Babak Shabani $^{1} \cdot$ Javad A. Mehr $^{1} \cdot$ Giles Thomas $^{2}$
}

Received: 20 September 2021 / Accepted: 7 February 2022 / Published online: 3 March 2022

(c) The Author(s) 2022

\begin{abstract}
T-foil and stern tabs were installed on a wave-piercing catamaran (Incat Tasmania Hull 061) to improve ship motions and passenger comfort. More than 40 total effective hours of sea trials were conducted by the US Navy in 2004, encountering sea states 4-5 in the Atlantic Ocean near the United Kingdom. In this paper the influence of a ride-control system (RCS) on the heave and pitch response amplitude operator (RAO) of the full-scale high-speed catamaran was investigated using the sea trial data. The reduction in motion sickness incidence (MSI) was estimated in order to examine the effectiveness of the RCS in improving passenger comfort. With the existing control algorithm, the vertical accelerations were found to be best controlled by the active T-foil working together with the active stern tabs, while the pitch RAO was mainly mitigated by deploying only the stern tabs. About a $23 \%$ reduction was observed in the peak heave RAO with deployment of an active T-foil. The MSI can be reduced by up to $23 \%$ with respect to the cases with stern tabs only, depending on the encountered wave conditions, based on ISO recommendation for MSI calculation of a 2-h seaway passage.
\end{abstract}

Keywords Wave-piercing catamaran $\cdot$ Ride-control system $\cdot$ T-foil deployment $\cdot$ Motion sickness incidence $\cdot$ Full-scale sea trial

\section{Introduction}

\subsection{Background}

Roll-on-roll-off (Ro-Ro) vessels have an important role in maritime transportation due to their ability to carry large number of passengers, cargo, and vehicles. In 2019, Ro-Ro vessels contributed $72 \%$ of the total 2.2 million vessels that called into the main ports in the European Union [1], i.e. that embarked, disembarked or handled freight. The increasing demand for high-speed transportation has pushed the evolution of Ro-Ro ferries towards larger capacity and higher speed. In the family of high-speed large Ro-Ro vessels, the catamaran is often a popular choice, owing to its large deck area, low wave-making resistance and high transverse stability $[2,3]$.

Chun-Yu Lau

chunyu.lau@utas.edu.au

1 School of Engineering, University of Tasmania, Private Bag 65, Hobart, TAS 7001, Australia

2 University College London, London, United Kingdom
It is essential to understand the motions of a vessel encountering waves to determine its operability or seaworthiness. The response amplitude operator (RAO) is the prevailing indicator of the vessel response in waves of different frequencies, despite that the vessel response is somewhat non-linear. Fang et al. [4, 5] investigated the heave and pitch RAOs for three catamarans in regular waves from $\mathrm{Fr}=0.3-0.5$, to validate the motion predictions from two numerical potential theories. Similarly, Tezdogan et al. [6] used three different numerical methods, namely conventional strip theory, high-speed theory without hull interaction, and high-speed with hull interaction, to generate RAOs and analyse vessel operability. These numerical results were compared to the experimental data collected from a $151 \mathrm{~m}$ Ro-Ro catamaran ferry travelling at $20 \mathrm{knots}$. The authors found that in most cases, the estimates of the conventional strip theory were aligned well with the measured results. Their analysis also extended to the prediction of Motion Sickness Incidence (MSI) and operability envelopes based on the seasonal wave scatter diagrams.

\subsection{Wave-piercing catamarans (WPCs)}

To push the speed limit and operability in rough seas, wave-piercing catamaran's (WPC) were developed from the 
conventional catamaran hull form, with addition of piercing bow edges on the demi-hull to reduce wave response [8], and a centre bow to provide reserve buoyancy and minimise deck diving [9]. Figure 1 shows the distinctive centre bow on the WPC 'HSV-2 Swift' with this vessel being central to the work presented in this paper.

There is a wide range of research papers that report on the frequency dependent motions of WPCs in waves, including slamming and seakeeping performance [10-19]. According to Fang and Chan [20], WPCs show excellent seakeeping characteristic relative to conventional catamarans in oblique sea, based on model test and numerical results of a $41 \mathrm{~m}$ WPC at 20 knots. As a leader in the design and manufacture of aluminium WPCs, Incat Tasmania constantly seeks the most optimised and refined system that can be used to further enhance the operability of their design through the installation of ride-control systems (RCS) and centre bow [7, 11, 13, 17, 20-24].

The RCS fitted on Incat Tasmania vessels generally consists of a single retractable T-foil at the aft end of the centre bow and two transom mounted trim tabs, as shown in Fig. 2. The T-foil on the vessel 'HSV-2 Swift' has two adjustable angles, which are strut angle and flap angle. When encountering high sea states, the RCS provides counter control forces to mitigate the motions, specifically heave, pitch, and roll. In contrast, when the vessel is travelling in calm water, the T-foil can be retracted above the water surface to minimise the hydro-resistance and improve the fuel efficiency.

\subsection{Ride-control system algorithms}

The individual hydraulic mechanisms of each control surfaces allow the RCS to react actively upon encountering a wave train. AlaviMehr et al. [26] performed a comprehensive analysis on the capability of the RCS, by measuring the heave and pitch response on a $2.5 \mathrm{~m}$ model of a $112 \mathrm{~m}$ WPC that was excited by deflecting the T-foil and the stern tabs separately. Used to validate theoretical calculations, their study on

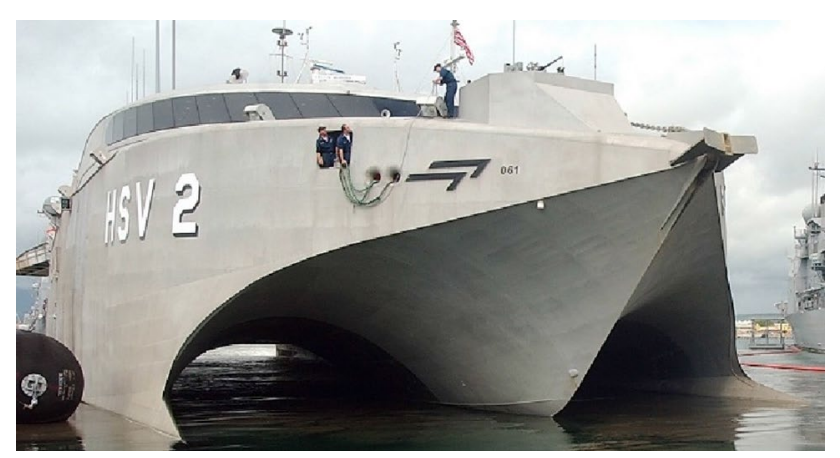

Fig. $198 \mathrm{~m}$ Incat Tasmania Hull 061 WPC showing prominent wavepiercing centre bow [7] the RCS control responses provided a sound foundation for optimisation of the control algorithms. In following research [27] in 2017, the influence of different control algorithms (listed in Table 1) on WPC motions was investigated. In terms of the slew rate, each algorithm can be categorised as linear (the control surfaces deflect linearly following the vessel motions' rate and remain within their maximum range of physical movement) and non-linear control (the control surfaces move at maximum slew rate between their extreme positions, thus generating maximum control force at all times). They reported that the non-linear pitch control algorithm can significantly reduce the peak pitch motion by up to $70 \%$ in $60 \mathrm{~mm}$ ( $2.7 \mathrm{~m}$ full scale) regular head waves, and by $50 \%$ in $90 \mathrm{~mm}$ (4 m full scale) regular head waves.

Smith [28] identified the algorithm applied to the sea trials on HSV-2 Swift to be pitch damping on the T-foil strut angle, and the stern tabs were always controlled by $60 \%$ pitch damping and $40 \%$ roll damping. However, as will be discussed, the characteristics of both pitch damping and stiffness are expected to be observed in the motion response, due to the phase lag between control surfaces deflection and pitch motion.

\subsection{Motion response of WPC fitted with RCS}

AlaviMehr et al. [27] also investigated the phase lag between control surfaces deflections, the wave profile, and the motions. Through tank tests on the $2.5 \mathrm{~m}$ model in regular waves, they concluded that the control force of the pitch

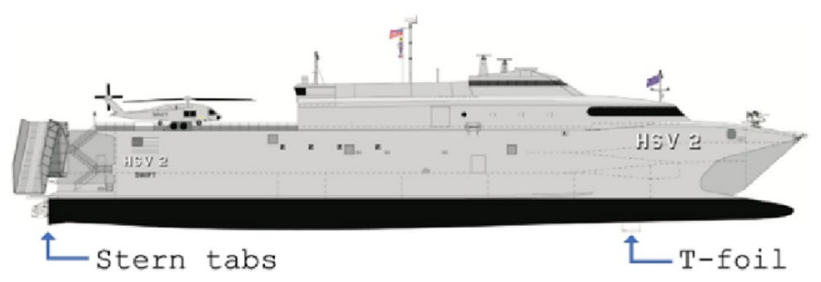

Fig. 2 Incat Hull 061-HSV-2 swift ride-control surface locations [25]

Table 1 Summary table of T-foil control options and algorithms

\begin{tabular}{lll}
\hline Control option & Control mode & Control term \\
\hline Active & Pitch control & Stiffness \\
& & Damping \\
& Heave control & Stiffness \\
& & Damping \\
& Local motion control & Stiffness \\
& & Damping \\
Passive & N/A & \\
Retracted & N/A & \\
\hline
\end{tabular}


damping algorithm can be represented by a combination of pitch damping and stiffness control, due to the phase lag between the demand for each control surfaces deflection and its response. Unsurprisingly, this phase lag was found to be much more significant at higher frequencies than at lower frequencies, according to AlaviMehr et al. [29], and the phase lag was found to fluctuate over a range of $90^{\circ}$ regardless of the type of surface or control method [27]. This observation from the model test is also seen in the full-scale sea trial data that will be discussed in the present study (see Sect. 3.3).

In 2004, the US Navy conducted a comprehensive suite of sea trials on a $98 \mathrm{~m}$ WPC, HSV-2 Swift, to assess its seakeeping and structural capability [30]. During the sea trials, two methods of activation of the RCS were used: T-foil with stern tabs, and stern tabs alone-thus, the effectiveness of an active T-foil could be assessed from the sea trials data. Bachman [30] linked the activation of the T-foil to the reduction of pitch angle Root Mean Square (RMS) as well as heave RMS throughout all headings at high speeds.

Jacobi et al. [31] further investigated the same dataset by applying RAO analysis, which investigated the frequency and wave spectrum dependent motions, instead of timeaveraging the motions into a simple RMS. They reported a $20 \%$ reduction in the maximum heave RAO by deploying an active T-foil when the vessel travelled at 30 knots. They also found that the effect on the pitch RAO of activating the T-foil was insignificant in both full-scale data and the prediction of the two-dimensional green function time-domain strip theory (BEAMSEA) developed by Holloway and Davis [32-34]. They suggested that due to the reduced distance between the T-foil and centre of mass of the vessel, the main contributor to pitch motion reduction at high speed was the trim tabs at the transom rather than the T-foil. However, another reason is suggested in Sect. 3.3 of the present study.

Recently, Davis [35] expanded the test conditions applied to the BEAMSEA model to assess the motion of WPC fitted with RCS. He included the various combinations of active or passive T-foil deployment, algorithm, and slew rate of the RCS at high speed $(\mathrm{Fr}=0.64)$. It was similarly observed that in regular waves the pitch motion can be controlled with active stern tabs alone, while heave can only be well controlled with the T-foil deployment. He also further noted that the reduction in RAO was highly dependent on the maximum control slew rate, as well as the application of nonlinear control terms. These findings agreed with the towing tank result of AlaviMehr et al. [27].

\subsection{Motion sickness incidence of WPC}

As studied in the pioneering work on motion sickness of O'Hanlon and McCauley [36], motion sickness is caused predominantly by vertical accelerations. Therefore, the ability of RCS to reduce vessel responses in waves is of significant benefit in the development of high-speed lightcraft including WPCs.

To quantify the influence of vessel motions on passenger comfort, the Motion Sickness Incidence (MSI) metric was proposed, defined as the percentage of unacclimatised subjects who would experience sickness for a given duration of exposure to motions. O'Hanlon and McCauley [36] suggested that MSI is a function of frequency and amplitude of vertical acceleration. Their study found that ordinary humans are sensitive to sinusoidal accelerations at a frequency in the vicinity of $0.2 \mathrm{~Hz}$. The research was later continued by McCauley et al. [37] wherein an empirical model for MSI under conditions including pitching and rolling motions was investigated. However, it was found that the angular motion had no significant effect on MSI.

A similar result was found by Lawther and Griffin [38], in which they quantified the MSI with the translational and rotational motions based on experimental data. The correlation between motion sickness and the acceleration time histories was analysed, and a strong connection was found between MSI and vertical motion, influenced by both magnitude and duration of exposure, while the angular accelerations were not found to be significant in inducing motion sickness. MSI has been widely applied for passenger comfort research [35, 39-41], and it has also been included in the ISO standard 2631-1 since 1997, which was reviewed recently in 2021 [42].

The MSIs during a 60-min journey on a WPC travelling at 40 knots under various ride-control condition were predicted by Davis [35] using the BEAMSEA code [34]. He found that MSI is highly dependent on the encountered significant wave height and the longitudinal location within the vessel. He also suggested that by deploying a T-foil and stern tabs with a pitch damping control mode, the MSI for 90-min exposure duration can be reduced by up to $23 \%$ compared to a bare hull.

The reduction of RAO due to RCS activation in those seakeeping trials will be investigated in this paper. Since there were two states of the RCS in the sea trials, (T-foil with stern tabs, and stern tabs only) the influence of T-foil deployment on the motions will be discussed in this paper.

To further investigate the effect of T-foil activation on the passenger comfort, i.e. the difference between MSI with stern tabs only, and with both T-foil and stern tabs, on a full-scale WPC (HSV-2 Swift), the remainder of this paper will present analyses of sea trials data using a linear regression model. The reductions in MSI due to T-foil deployment for a 120-min journey will be predicted under different significant wave height, encountered peak wave frequency and speed conditions. The MSI in the HSV-2 Swift passenger cabin will also be predicted and plotted in the form of a 3D surface, with the aim of demonstrating the influence of the 
longitudinal and transverse location on the passenger comfort in oblique seas.

\section{HSV-2 swift sea trials and data collection}

\subsection{HSV-2 swift}

High-speed vessel 2 swift (HSV-2 swift) is a large wavepiercing catamaran (WPC). These vessels provide fast, efficient, and economical sea transportation for both commercial and military use [9, 27, 43]. The RCS actively controls the hull motions during voyage, and are customised to suit the needs of each WPC. HSV-2 Swift RCS includes a retractable T-foil with strut and flap control at the aft of the centre bow, and two individual controlled stern trim tabs. The T-foil provides vertical forces to counter heave and pitch motions. Two trim tabs at the demi-hull stern generate a lift force at the transom to maintain the desired vessel dynamic trim, and to reduce pitch and heave. The stern tabs can also counterbalance roll motion when they are operated differentially.

Full-scale sea trials datasets were acquired on the HSV-2 Swift wave piercing catamaran, shown in Fig. 3, which was built by Incat Tasmania. Details of the trials and data acquisition will be discussed in the next section. The main particulars of the vessel are shown in Table 2.

\subsection{Sea trials and data acquisition}

The sea trials were performed in the North Atlantic Ocean, near the coasts of Norway and the United Kingdom, in the northern summer of 2004. To examine the operability and structural response of the vessel, the trials were conducted in moderate to rough seas, which is generally more severe than the wave environment experienced on a typical route

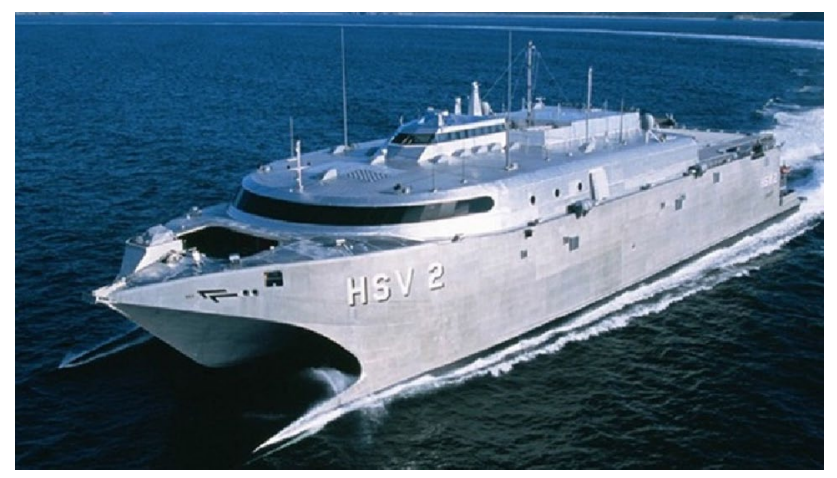

Fig. $398 \mathrm{~m}$ Incat Tasmania aluminium high-speed wave-piercing catamaran HSV-2 Swift [7] of a commercial Ro-Ro ferry in service. Specifically, the highest encountered significant wave height $\left(H_{\mathrm{s}}\right)$ was $3.7 \mathrm{~m}$ (Douglas sea state 5), and the average encountered $H_{\mathrm{s}}$ was about $2.2 \mathrm{~m}$ (Douglas sea state 4 ).

The trials consisted of 21 octagons, each encountering a different combination of significant wave height, wave spectrum, vessel speed and state of deployment of the T-foil. In general, every octagon included at least five legs, which comprised the five headings of head seas, bow-quartering seas, beam seas, stern-quartering seas, and following seas, as shown in Fig. 4. Around half of the octagons were completed by manoeuvring to port by $45^{\circ}$, while the rest were completed by turning to starboard.

The typical procedure of the sea trials started with the visual observation of the wave direction. The dominant wave direction was recorded, as well as secondary waves and swell if they existed. Then HSV-2 Swift was turned to head seas and maintained speed and heading until steady, and then all the instruments on board started recording. The heading was adjusted $45^{\circ}$ to port or starboard and testing continued for another leg of the trial. Generally, the speed and course were maintained for $20 \mathrm{~min}$ in head-sea case, $30 \mathrm{~min}$ in beam-sea case, and $40 \mathrm{~min}$ in following-sea case, to encounter more waves for maintaining statistical accuracy. After five (or sometimes all eight) legs of the sea trial were completed, the data collection under this particular sea state, speed and T-foil deployment was considered to be complete [30]. More than $40 \mathrm{~h}$ of data were measured throughout the sea trials undertaken specifically by the Naval Surface Warfare Centre Carderock Division (NSWCCD).

To acquire motion and wave data from the vessel HSV-2, instrumentation including accelerometers and a wave height

Table 2 HSV-2 swift main parameters [25, 30]

\begin{tabular}{ll}
\hline Length overall (LOA) & $97.22 \mathrm{~m}$ \\
Length water-line (LWL) & $92.00 \mathrm{~m}$ \\
Beam & $26.60 \mathrm{~m}$ \\
Demihull beam & $4.50 \mathrm{~m}$ \\
Draft & $3.43 \mathrm{~m}$ \\
Deadweight & 670 tonnes \\
Maximum speed & 42 knots \\
\hline
\end{tabular}

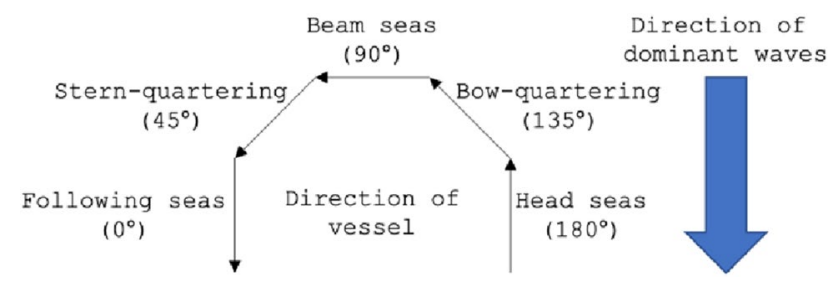

Fig. 4 Typical sea trial manoeuvre pattern 
radar were installed. Four three-axis accelerometers were located on the centreline at the bow, bridge, Longitudinal Centre of Gravity (LCG) and flight deck. All the accelerometers were sampled at $100 \mathrm{~Hz}$. This sampling frequency was appropriate since the frequencies of interest for motion and excitation were below $1 \mathrm{~Hz}$. Pitch and Roll were also recorded at the LCG using inclinometers [30, 44].

To enable comparison of runs in similar sea states, the significant wave height $\left(H_{\mathrm{s}}\right)$ (defined as $H s=4 \sqrt{m_{0}}$, where $m_{0}$ is the area under the encountered wave height spectrum) was evaluated. The encountered wave environment was monitored by the wave height meter WM-2, designed by the Tsurumi Seiki Co., Ltd. (TSK). It was installed at the bow to sample the wave profile before the water surface interacted with the hull. This microwave Doppler radar was engineered to measure the wave height from an unstable platform, such as a ship, with relative displacement compensation [45].

\subsection{Method of data analysis}

To investigate the hull motions when encountering waves, and hence to identify the influence of the RCS on motions and passenger comfort, vertical and angular motion of the vessel were examined. The analysis started with the heave motions (based on measured vertical acceleration) at the LCG, and these were extrapolated throughout the passenger cabin using the angular motions, to obtain the MSI distribution across the cabin. Lastly, dimensionless acceleration along the hull was analysed to yield a comprehensive understanding on the distribution of motions and MSI, as shown in Fig. 5.

Since the hull response is frequency dependent, most of the data processing and analysing were conducted in the frequency domain. To obtain a smoothed power spectrum density (PSD) for the encountered wave height, Welch's method with 8000-sample Blackman-Harris windowing (50\% overlap) was applied, employing the fast Fourier transform (FFT). The Blackman-Harris window was chosen due to its ability to detect nearby frequencies of vastly different amplitudes [46, 47].

The heave RAO is defined as the square-root of the ratio between the heave and wave height PSDs, like Eq. 1, while the angular (roll and pitch) RAOs depend on the wave slope spectrum rather than the wave height, as shown in Eq. 2.

Heave RAO $=\sqrt{\frac{\text { Encountered heave PSD }}{\text { Encountered wave height PSD }}}$,

Angular RAO $=\sqrt{\frac{\text { Encountered angular motion PSD }}{\text { Encountered wave slope PSD }} .}$

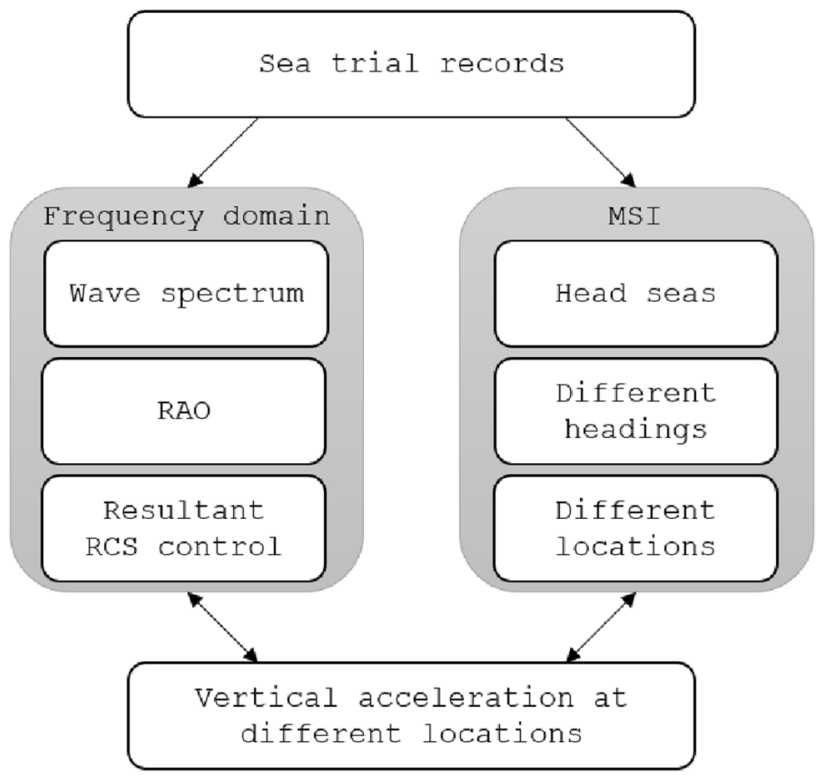

Fig. 5 Flow chart of data analysis in the present study

The encountered wave slope power spectrum of the $n$th sine wave in irregular waves is calculated as $\alpha_{n}=k_{n} \varsigma_{n}$, where $\alpha_{n}$ is the $n$th wave slope, $k_{n}$ is the $n$th wave number, and $\varsigma_{n}$ is the $n$th wave amplitude. In the sea trials location, the minimum water depth was about $130 \mathrm{~m}$ [48], which means it could be considered deep water for the waves shorter than $260 \mathrm{~m}$ [49]. In deep water, $k_{n}=\omega_{n}^{2} / g$, where $\omega_{n}$ is the $n$th wave frequency and $g$ is gravitational acceleration. Therefore, the wave slope PSD can be estimated by Eq. 3 for at least $\omega_{n}>0.5 \mathrm{rad} / \mathrm{s}$ approximately in the shallowest locations.

Encountered wave slope PSD $=\frac{\omega_{n}^{4}}{g^{2}}$ encountered wave height PSD.

The dimensionless wave encounter frequency $\varpi_{\mathrm{e}}^{*}$ is $\varpi_{\mathrm{e}}^{*}=2 \pi f_{\mathrm{e}} \sqrt{L_{\mathrm{WL}} / g}$, where the encounter frequency $f_{\mathrm{e}}$ is in $\mathrm{Hz}$ and $L_{\mathrm{WL}}$ is the water-line length.

According to ISO-2631-1 [42], MSI can be estimated by MSI $=K_{\mathrm{m}} a_{\mathrm{w}} \sqrt{T_{\mathrm{e}}}$, where $K_{\mathrm{m}}$ is the constant $1 / 3$, suggested by the ISO for a mixed population of unadapted males and females; $a_{\mathrm{w}}$ is the root mean square of frequency-weighted (Fig. 6) vertical acceleration, $a_{\mathrm{w}}=\left[\sum_{i}\left(W_{i} a_{i}\right)^{2}\right]^{0.5}$; and $T_{\mathrm{e}}$ is the exposure time in seconds.

A spatial shift method for time-domain vertical accelerations has been used for the HSV-2 Swift dataset to estimate the MSI distribution in the passenger cabin, and is verified in Sect. 3.6. The time-domain vertical acceleration translation at any point in the cabin can be written as Eq. 4 .

$\operatorname{Acc}_{\mathrm{C}}=\frac{X_{\mathrm{CA}}}{X_{\mathrm{BA}}}\left(\operatorname{Acc}_{\mathrm{B}}-\mathrm{Acc}_{\mathrm{LCG}}\right)+\frac{\mathrm{d}^{2}}{\mathrm{~d} t^{2}}\left[Y_{\mathrm{C}} \tan (\right.$ Roll angle $\left.)\right]+\mathrm{Acc}_{\mathrm{LCG}}$, 


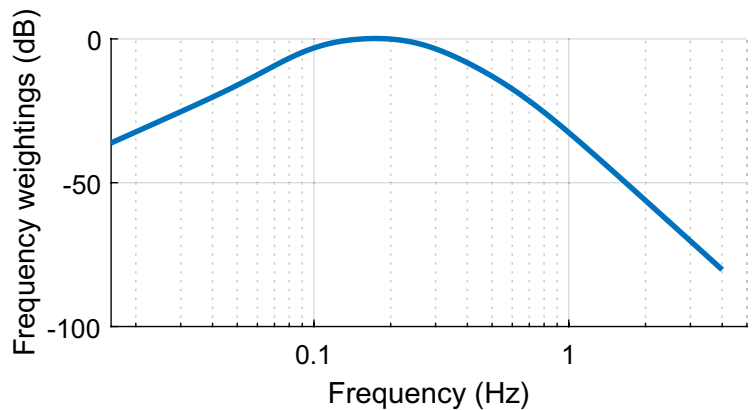

Fig. 6 Frequency weighting of motion sickness incidence evaluation [42]

where $X_{\mathrm{CA}}$ is the longitudinal distance between the LCG and the prediction location $C$; $X_{\mathrm{BA}}$ is the longitudinal distance between the location of a second accelerometer at $B$ and the LCG; and $Y_{\mathrm{C}}$ is the transverse distance between the prediction location and the LCG.

Since the superstructure of the vessel was isolated from the hull to enhance passenger comfort, the vibration measured on the superstructure, i.e. at the bridge, was found to be slightly lower than the value estimated from accelerations measured on the hull substructure, but a uniform scaling of 0.95 applied to accelerations measured on the substructure was found to give excellent agreement across the full frequency range of interest. Therefore, to fully simulate the environment in the passenger cabin, which is within the superstructure, this adjustment was used. Further details can be found in Sect. 3.6.

\section{Results and discussion}

\subsection{Time record of sea trial data}

Figure 7 shows typical time traces of HSV-2 Swift sea trials data for a short segment of two corresponding runs with deployed and retracted T-foil. Both datasets were recorded in a $2.2 \mathrm{~m}$ significant wave height in head seas at 35 knots. Normalised, instantaneous wave elevation at the bow, heave displacement at the LCG, and angular displacements and their rates are shown in the plots. A zero-phase noise filter $\left(4^{\text {th }}\right.$-order Butterworth cut off at $\left.0.5 \mathrm{~Hz}\right)$ was applied to all data in these plots. Records such as these provide crucial information on the external excitation and how the vessel responds. A phase lag was noticed between waves at the bow and motion at the LCG, but since the motion analysis in this study focuses on comparing the real part of the FFT, the phase shift due to wave measurement location makes no difference.

The activity of the T-foil and stern tabs can be observed in the plots on the left-hand side of Fig. 7. It should be noted that the stern tabs still actively counter pitch and roll motion, even with the T-foil retracted, as shown on the plots on righthand side of Fig. 7. According to the work of Smith [28], and the time records used in this study, it has been found that the T-foil strut angle was controlled by a pitch damping algorithm, while the control gain for the stern tabs was set to $60 \%$ pitch damping and $40 \%$ roll damping. There was no observable relationship between $\mathrm{T}$-foil flap angle and vessel motions or rates in time domain, as Smith [28] also suggested, therefore the applied algorithm cannot be identified solely by the time record.

\subsection{Influence of T-foil deployment on vessel motions at different speeds}

The motions analysis in this study focuses on heave and pitch motions, since according to ISO-2631-1 [42], motion sickness primarily depends on the vertical acceleration in the environment. Considering further that, based on the study of Jacobi et al. [31], the WPC motions are most significant in head seas, this part of the analysis concentrates on the heave and pitch RAOs in head seas.

To understand the vessel response at various frequencies and speeds, with and without the T-foil, the RAOs have been evaluated in head seas at three speeds: 20 knots, 30 knots, and 35 knots. Figure 8 shows a measured sample of the encountered wave height spectrum at 30 knots in head seas, along with the corresponding encountered JONSWAP spectrum that was generated using the measured significant wave height $(2.24 \mathrm{~m})$ and peak wave frequency $(1.04 \mathrm{rad} / \mathrm{s}$ or $\omega_{\mathrm{e}}^{*} \sim 3.0$ ), and with gamma $=2.0$. It was found that the measured encountered peak wave frequencies were quite consistent at different speeds. The average peak frequencies were 1.02, 1.00, and $1.04 \mathrm{rad} / \mathrm{s}$ at 20,30, and $35 \mathrm{knots}$, respectively.

Figure 9a, b show the RAOs for HSV-2 Swift encountering seas with a significant wave height of about $1.8 \mathrm{~m}$ at 20 knots. There is little difference between results with the T-foil deployed or retracted, for both heave and pitch RAOs. This was expected since the lift force generated by the T-foil is a function of the vessel speed, higher speed generating higher lift. Therefore, the ability of RCS is limited at low speeds.

The RAOs at 30 knots were evaluated (Fig. 9c, d) and compared with the work of Jacobi et al. [31], and show very high agreement. The data with and without $\mathrm{T}$-foil were measured at $H_{\mathrm{s}}=2.7 \mathrm{~m}$ and $2.3 \mathrm{~m}$, respectively.

At first, the authors expected the heave and pitch RAOs to approach unity at low frequencies, i.e. $\sim 0.1 \mathrm{~Hz}$ or $\omega_{\mathrm{e}}^{*}=2.0$, since the ship motion is dominated by the hydrostatic term in long waves. However, this was not the case for the pitch RAO. According to the strip theory proposed by Salvesen et al. [50], the governing equation of pitch motion consists 
a
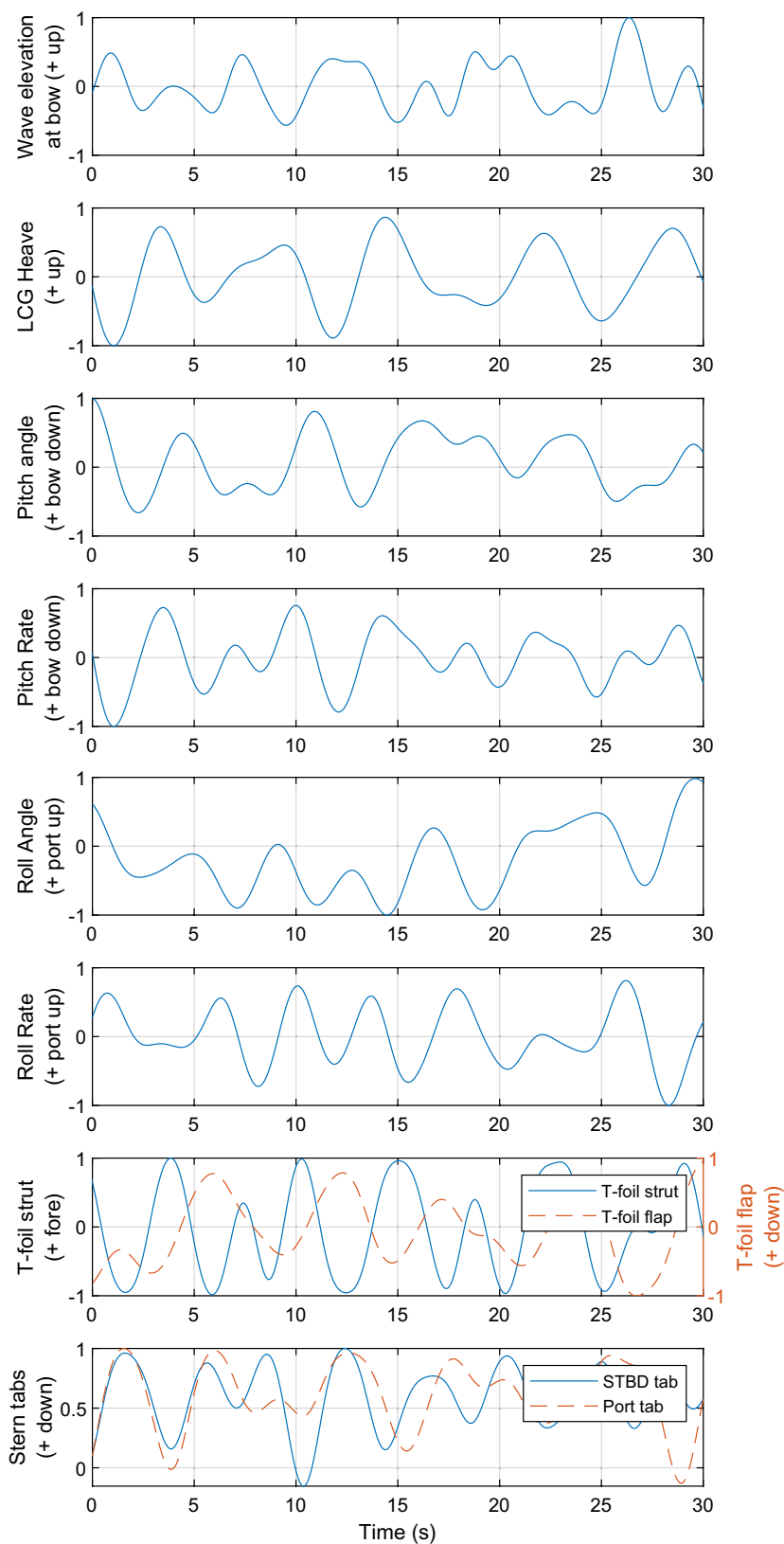

b
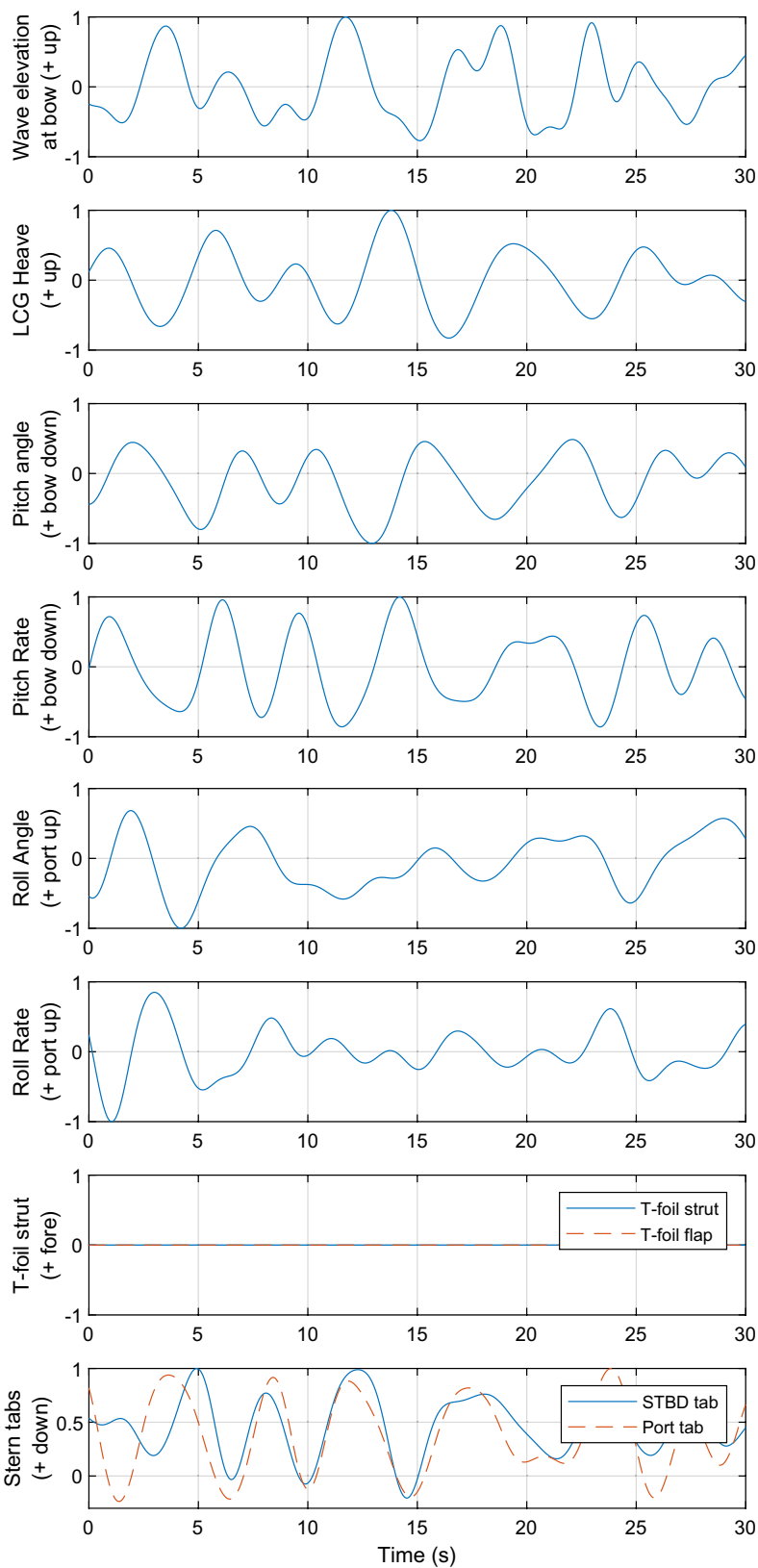

Fig. 7 Normalised ship motion and ride-control activity recorded during trials of HSV-2 98m Incat wave piercing catamaran in head seas with a $2.2 \mathrm{~m}$ significant wave height at a speed of 35 knots a T-foil deployed with stern tabs b Stern tabs only

of added-mass and damping terms, which included $1 / \omega^{2}$ in their coefficients. Thus, it often predicts that the pitch changes rapidly at low frequencies, and tends to zero at extra low frequencies, e.g. $<0.1 \mathrm{~Hz}$ or $\omega_{\mathrm{e}}^{*}<2.0$ [33]. One must also bear in mind that because stern tabs were always active in both cases, the RAOs were not reflecting the response of the bare hull.

The lower pitch RAOs at low frequency were consistent with the pitch stiffness ride-control evaluation in Davis's work [35]. Although we identified in the previous section that this WPC probably utilised damping control in its RCS, the resultant force of the control surfaces will in practice appear as a combination of damping and stiffness due to the phase lag between the stern tabs deflection and vessel [27]. Thus, the pitch RAO for the case of tabs only is closer to 1 at low frequencies due to the effective pitch stiffness ride control by the stern tabs. 


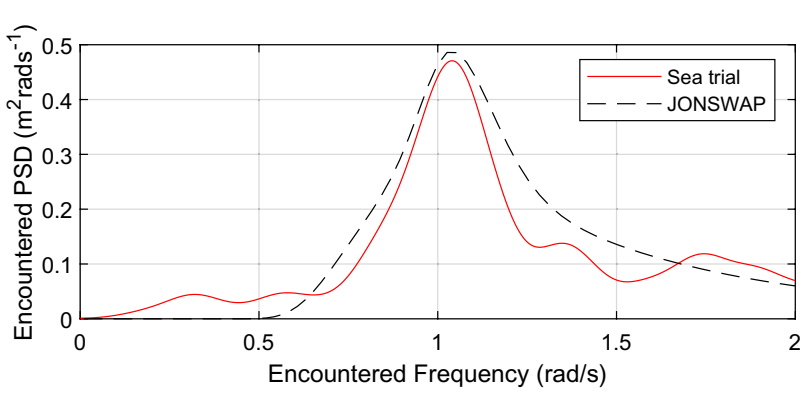

Fig. 8 Measured encountered wave spectrum at 30 knots with JONSWAP spectrum $($ gamma $=2.0)$

Consider now these results in the context of the ISO MSI frequency weighting, which reaches its maximum at $\sim 0.17 \mathrm{~Hz}$ or $\omega_{\mathrm{e}}^{*} \sim 3.3$. At this frequency, the heave RAO reduced by $\sim 30 \%$ on deployment of the active T-foil, a notable improvement compared with 20 knots, which can be explained by the higher speed generating larger lift. Similar observation is also noted near the catamaran's first rigid body natural frequency at $\omega_{\mathrm{e}}^{*} \sim 4.5$, where the heave RAO reduced by $\sim 20 \%$ with deployment of the T-foil. Indeed, the most effective frequency range of the T-foil for reducing heave at 30 knots is $3 \leq \omega_{\mathrm{e}}^{*} \leq 5$. The motions at high frequency, i.e. above $\sim 0.33 \mathrm{~Hz}$ or $\omega_{\mathrm{e}}^{*}=6.5$, tend to zero as expected, as the vessel becomes much longer than the waves.

The RAOs at 35 knots $\left(\mathrm{Fr}=0.60 ; H_{\mathrm{s}}=2.2 \mathrm{~m}\right)$ are plotted in Fig. 9e, f, along with numerical results predicted by Davis [35] using the BEAMSEA code [32-34]. Davis compared the effect of the T-foil and tabs to the case of stern tabs only, using different RCS algorithms, for a $106 \mathrm{~m}$ WPC travelling at 40 knots $(\mathrm{Fr}=0.64)$ in $3 \mathrm{~m}$ head seas. Plotted in this figure are Davis's results for pitch damping and pitch stiffness algorithms. Although the conditions between the sea trials and numerical simulations were not identical, the results demonstrate the same nature of motion reduction on deployment of the T-foil.

Comparing the peak heave RAOs with deployment of the T-foil, we see about $23 \%$ reduction in the sea trials, consistent with a predicted $\sim 20 \%$ in the work of Davis [35] with the RCS used in a pitch damping mode, and about $40 \%$ when using pitch stiffness control. More broadly, the T-foil produced significant reduction in heave RAO for all frequencies $\omega_{\mathrm{e}}^{*} \geq 4.0$ at high speed in both sea trials and numerical analysis. The most effective frequency range of the T-foil in reducing heave RAO was $4 \leq \omega_{\mathrm{e}}^{*} \leq 6$ at 35 knots, compared with $3 \leq \omega_{\mathrm{e}}^{*} \leq 5$ at 30 knots.

In contrast, the influence of the bow-mounted T-foil on pitch was not as significant as for heave, even though the T-foil was in pitch control. This is aligned with the work of Davis [35], in which pitch motion was well controlled by stern tabs only.
It is interesting that again the pitch RAOs obtained from the sea trials were generally below 1.0 at low frequencies, regardless of the T-foil deployment, in contrast to the pitch damping algorithm results modelled using BEAMSEA, which starts at $\sim 1.0$, but in agreement with the modelled pitch stiffness algorithm results, which start at $\sim 0.7$. This implies that there was at least a component of pitch stiffness control, at least at low frequencies, in the sea trials.

Finally, the results from BEAMSEA appear to be shifted to the right, which may in part be because the simulations were not based on exactly the same hull form or Froude number.

\subsection{An explanation for the difference between the RCS control algorithm and the control outcomes}

It was noted in the preceding section that the sea trials data exhibited characteristics of pitch stiffness control, although the RCS was presumably configured to a pitch damping control mode. The possible reason is that there will inevitably be a lag in the RCS due to its own system inertia, and any such lag will manifest itself as a control based on an integrated form of the intended motion input. For example, since displacements lag velocities, ideal control forces based on velocities (i.e. damping) will in practice contain a small component based on displacements (i.e. stiffness). This has also been noted by AlaviMehr et al. [27].

More specifically, factors contributing to the control lag include: 1 . control surface mass inertia; 2 . hydraulic system response time; 3 . maximum slew rate; and 4. inertia of the water surrounding the control surface. According to the model test result of AlaviMehr et al. [27], the phase lead of the T-foil to pitch motion was $60^{\circ}$, while the phase lag of tabs to pitch motion was $120^{\circ}$ at $\omega_{\mathrm{e}}^{*}=2$, at a speed of $\mathrm{Fr}=0.6$ in the pitch damping control mode. The phase lag or lead for a corresponding $2.5 \mathrm{~m}$ WPC scale model in regular waves was extracted from Fig. 10 and is summarised in Table 3 [27].

The resultant ratio of damping to stiffness input in the control algorithm can be estimated by analysing the phase lag. Since pitch rate leads pitch angle by $90^{\circ}$, the ratio of damping to stiffness can be determined by calculating the zero-crossing timing of the deflections separately. For example, at the frequency $\omega_{\mathrm{e}}^{*}=2$, the T-foil and tabs deflect with a phase lag of $30^{\circ}$ relative to the pitch rate. So the resultant damping to stiffness ratio can be estimated as 2:1 as shown in the Eq. 5.

$\left(1-\frac{30}{90}\right): \frac{30}{90}=0.67: 0.33=2: 1$.

Since the phase lag changes across the frequency spectrum, the effective RCS algorithm, i.e. ratio of pitch damping 

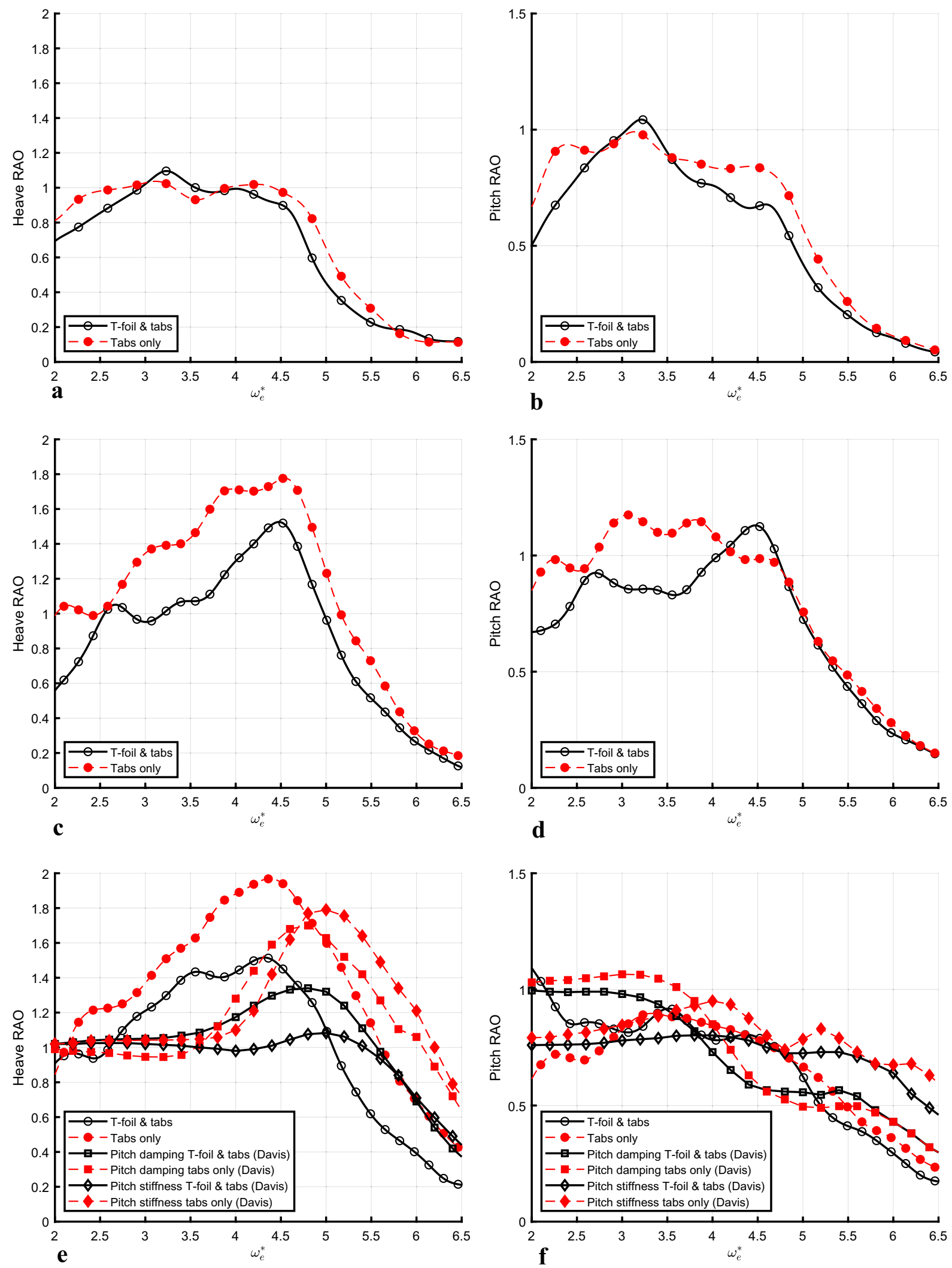

Fig. 9 Response amplitude operators with T-foil and without T-foil of a wave piercing catamaran in head seas a heave at 20 knots $\mathbf{b}$ pitch at 20 knots $\mathbf{c}$ heave at 30 knots $\mathbf{d}$ pitch at 30 knots e heave at 35 knots

f pitch at 35 knots. For comparison note that the results of Davis in e and $\mathbf{f}$ were for a slightly different hull form with a length of $106 \mathrm{~m}$ and at a speed of 40 knots 

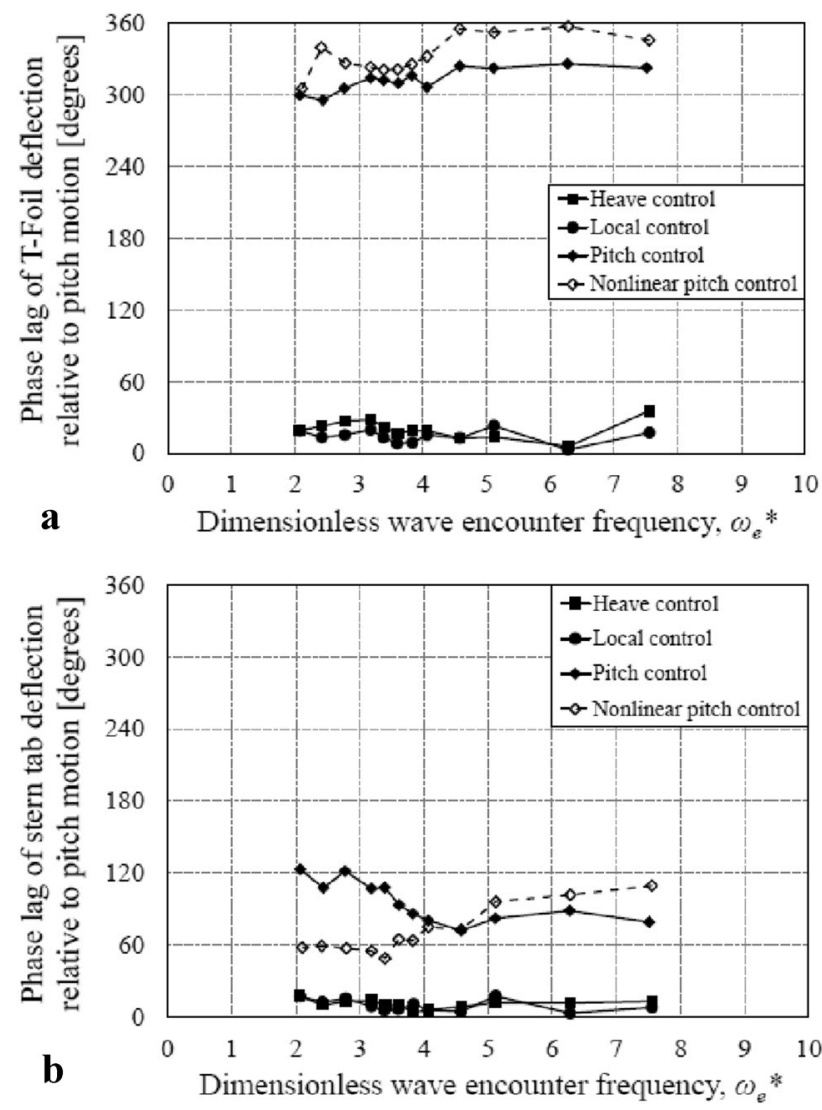

Fig. 10 Phase lag of a T-foil $\mathbf{b}$ stern tabs deflection relative to pitch motion on a $2.5 \mathrm{~m}$ model-scale $\mathrm{WPC}$ at $\mathrm{Fr}=0.61$ and $90 \mathrm{~mm}$ wave height [27]

Table 3 Phase lag in degrees between control surfaces deflection relative to pitch motion and rate at $\omega_{\mathrm{e}}^{*}=2$ and 6 at $\mathrm{Fr}=0.61$ model scale (\# means anti-phase) [27]

\begin{tabular}{llllll}
\hline$\omega_{\mathrm{e}}^{*}$ & \multicolumn{2}{l}{ Phase lag (pitch rate) } & & \multicolumn{2}{l}{ Phase lag (pitch angle) } \\
\cline { 2 - 3 } \cline { 5 - 6 } & T-foil & Stern tabs & & T-foil & \multicolumn{2}{l}{ Stern tabs } \\
\hline 2 & 30 & $210\left(\right.$ or $\left.30^{\mathrm{a}}\right)$ & & -60 & 120 \\
6 & 50 & $170\left(\right.$ or $\left.-10^{\mathrm{a}}\right)$ & & -40 & 80 \\
\hline
\end{tabular}

to stiffness input, is influenced by $\omega_{\mathrm{e}}^{*}$, even though the programmed control algorithm remains unchanged.

The estimated resultant algorithms at high and low encounter frequencies are given in Table 4, showing that the resultant ratio not only varies with frequency, but also depends on the control surface. Although the exact phase lag of the vessel HSV-2 Swift was not able to be extracted from the sea trials data, the phase lag recorded by another WPC model with similar hull and RCS were analysed for reference.

Based on these estimates of the resultant algorithm ratio, the control algorithm applied to the RCS may benefit from
Table 4 Estimated resultant damping and stiffness ratios of RCS control surfaces at $\omega_{\mathrm{e}}^{*}=2$ and 6 based on model-scale WPC experiment

\begin{tabular}{lll}
\hline Damping: stiffness ratio & $\omega_{\mathrm{e}}^{*}=2$ & $\omega_{\mathrm{e}}^{*}=6$ \\
\hline T-foil strut deflection & $0.67: 0.33$ & $0.44: 0.56$ \\
Stern tabs deflection & $0.67: 0.33$ & $0.89: 0.11$ \\
\hline
\end{tabular}

phase compensation to minimise the vessel motions, suggesting that further reduction in hull response may be possible by fine-tuning the algorithm.

\subsection{Motion sickness incidence in head seas}

Motion sickness incidence (MSI) is calculated from the acceleration measured at the LCG, using the method in ISO-2631-1 [42], and are for $2 \mathrm{~h}$ exposure, unless otherwise stated.

To interpolate the head seas MSI value for different speeds and wave heights, a linear regression was fitted, which is visualised in Fig. 11a along with the raw MSI data. The sea trials data were segmented into 10-min windows, with $50 \%$ overlap, to reduce the random error from each sea trail run. Based on 59 observations in head seas, the linear model obtained coefficient of determination $\left(R^{2}\right)=0.981$, and adjusted $R^{2}=0.978$, which indicate it is representative without overfitting.

According to the regression, the MSI value is highly dependent on the speed of the vessel $\left(p=6.2 \times 10^{-20}\right)$, significant wave height $\left(p=5.7 \times 10^{-8}\right)$, and peak encountered wave frequency $(p=0.0001)$. The influence of T-foil deployment on MSI can clearly be identified by comparing the cases of T-foil with tabs, and stern tabs only.

Unsurprisingly, the effectiveness of the T-foil in reducing MSI increased with speed, as shown in Fig. 11b, with MSI reduced by up to $23 \%$ at 35 knots and at mid sea state ( $\sim 1.6 \mathrm{~m}$ wave height). Although the MSI reduction was understandably slightly reduced in higher seas due to the larger denominator, about $15 \%$ was still achieved at the highest significant wave height at 35 knots. On the other hand, the effectiveness of an active T-foil at 20 knots is unclear, which aligns with the previous vertical motion findings.

Analysing the fitted regression more closely, we find that the ability of the T-foil deployment to reduce MSI in head seas is most strongly influenced by the vessel speed $\left(p=3.8 \times 10^{-12}\right)$, followed by a minimal dependence on peak encountered wave frequency $(p=0.58)$, with the wave height $(p=0.68)$ having no significant effect.

The conclusion is that deploying the T-foil with active stern tabs can always improve passenger comfort regardless of the $H_{\mathrm{s}}$ or wave frequency if the speed is over 20 knots. On the other hand, wave height and frequency are critical factors for the MSI in head seas, so the ability of 

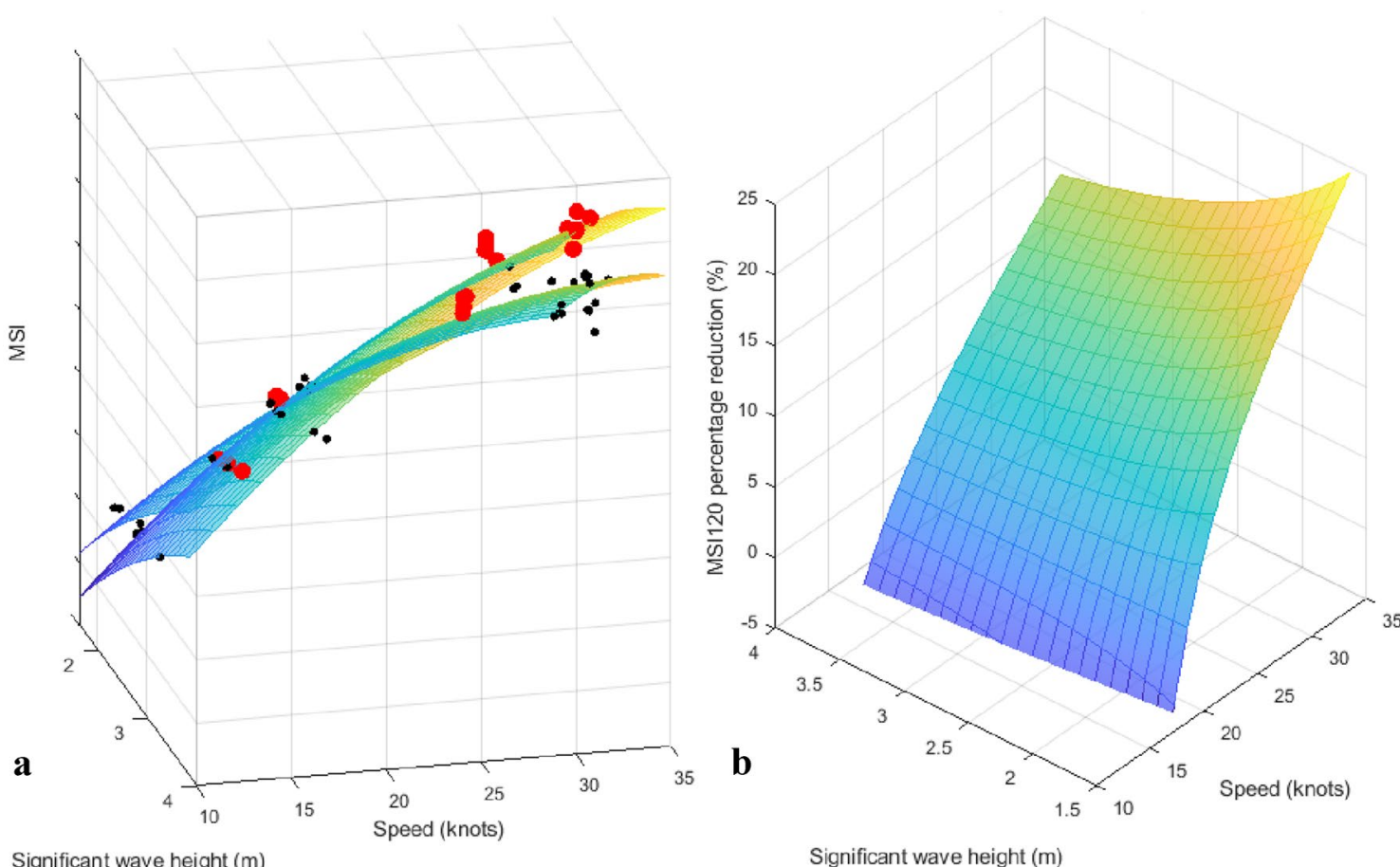

Significant wave height (m)

Fig. 11 a 3D plot of MSI with T-foil and tabs deployed (small, black markers), and with stern tabs only (large, red markers) in head seas b 3D plot of MSI percentage reduction due to T-foil deployment in head seas

the T-foil to reduce MSI independently of the wave spectrum is an important finding.

\subsection{MSI at different headings}

Figure 12 shows the influence of headings on the MSI calculated at the LCG at 35 knots based on sea trials data. MSI has been normalised by dividing the maximum value for improved illustration. As expected, the highest average MSI can be found in head seas, and the average MSIs declined as the encountered waves approach the stern. There is an outlier in bow-quartering seas, because the encountered peak wave frequency experienced in this run was $0.18 \mathrm{~Hz}$, which is very close to the most sensitive frequency $(0.17 \mathrm{~Hz})$ for MSI according to ISO-2631-1 [42]. Excluding the outlier, the MSI in bow-quartering seas was generally only half of the head seas MSI, while beam and other headings only experienced less than a quarter of the head seas MSI.

The cases of tabs with T-foil deployed, and stern tabs only, are also indicated in the plot by colour. However, in spite of over $40 \mathrm{~h}$ of full-scale data, comprising over 150 runs, no firm conclusions about the effect of T-foil deployment in oblique seas can be drawn from these trials due to the large number of variables.

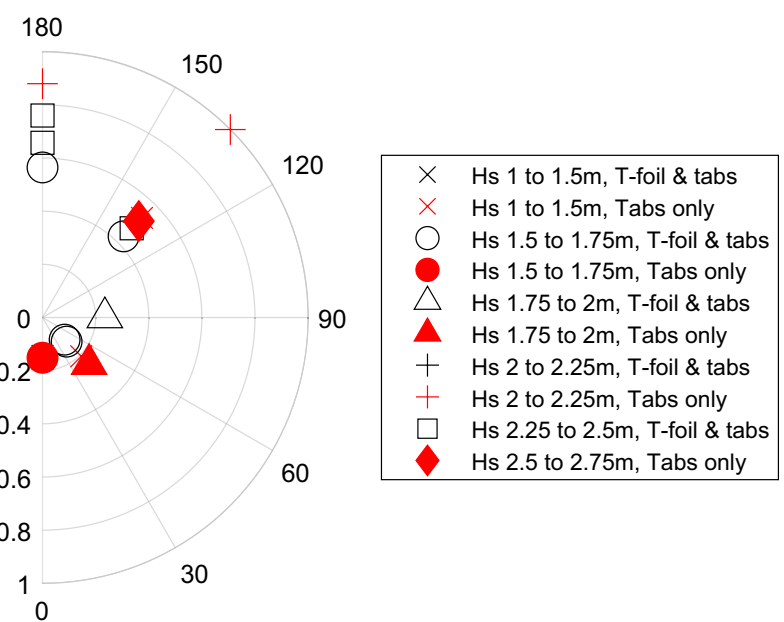

Fig. 12 Normalised MSI in different headings in sea trials at 35 knots, groups by significant wave height and T-foil activation (Port mirrored to starboard)

\subsection{MSI throughout the passenger cabin}

As the purpose of MSI assessment is to provide insight into the reaction of a mixed, unadapted population to periodic motion [42], it is more meaningful to compute the MSI at different locations in the passenger cabin, rather than just on the vehicle deck or at the LCG. 
There were four accelerometers installed on board during the sea trial, but none of them was in the passenger cabin. Thus, in the present study the vertical accelerations were extrapolated to different locations on board, as described in the Sect. 2.3. To confirm the validity of the extrapolation, estimated and measured vertical accelerations at the bridge in the time domain are plotted in Fig. 13a with a $\sim 0.95$ factor correction, showing no observable difference. Across all runs, and at all instrumented locations other than the LCG (i.e. bow, bridge, and flight deck), excellent agreement in the RMS acceleration is further demonstrated in Fig. 13b in more than 700 observations.

By this method, the distribution of normalised MSI inside the passenger cabin was evaluated. The $X$ (longitudinal) and $Y$ (transverse) coordinates were based on the HSV-2 Swift general arrangement, and the $Z$ (vertical) coordinate was set to $0.7 \mathrm{~m}$ above the deck level. The $X=0 \mathrm{~m}$ is set at the stern, while $Y=0 \mathrm{~m}$ is set at the centreline of the vessel. In the case of $2.3 \mathrm{~m}$ bow-quartering sea at 30 knots with the T-foil, chosen because it demonstrates the MSI distribution in oblique headings at high speed, the highest MSI can be found at the corner of the cabin facing the encountered waves, i.e. starboard fore, as shown in Fig. 14a. It was unsurprising to see the other fore corner also experiencing relatively strong MSI, while the aft of the vessel was least affected by the motion.

Figure $14 \mathrm{~b}$ shows the percentage reduction in MSI on deployment of the active T-foil, by comparing the data in Fig. 14a with a T-foil retracted case (30 knots bow-quartering sea, $H_{\mathrm{s}}=2.2 \mathrm{~m}$ ). This was about $10 \%$ on average, and up to $14 \%$. The reduction at the stern was higher than at the bow, which was not expected because the T-foil was fitted towards the bow, close to $80 \%$ of the water-line length from the transom and very close to the forward limit of the passenger cabin. But if we consider the fact that the influence of T-foil on heave RAO was much more significant than on the pitch RAO, it was reasonable to find that MSI reduced
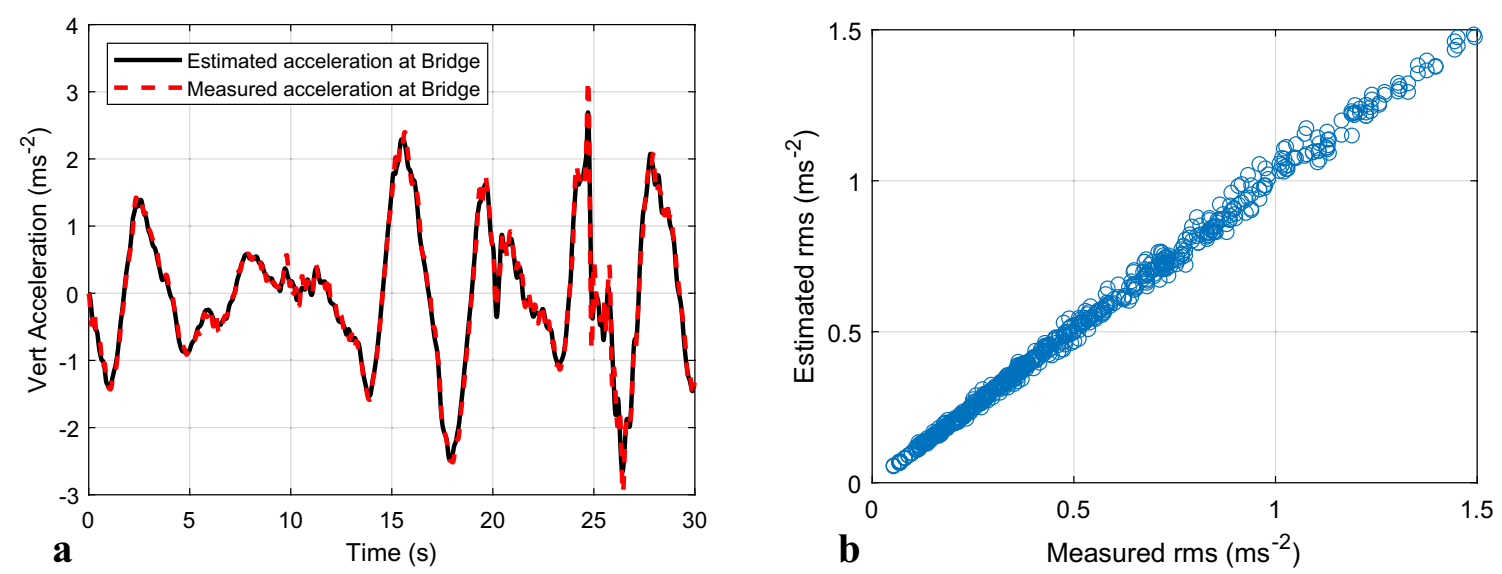

Fig. 13 Comparison of estimated and measured vertical accelerations: a a time-domain sample at the bridge b RMS from different runs at the various accelerometer locations on the vessel
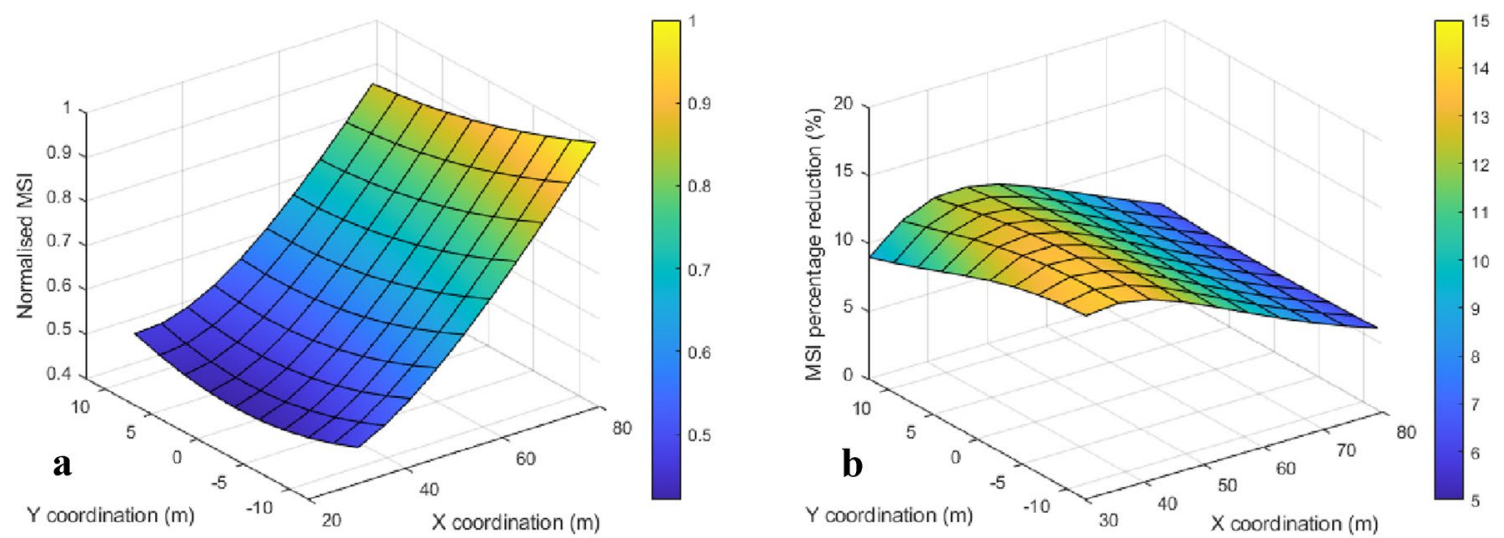

Fig. 14 98m WPC passenger cabin: a MSI distribution b MSI percentage reduction with deployment of the active T-foil (in addition to stern tabs) at 30 knots with significant wave height of 2.2-2.3 $\mathrm{m}$ in an oblique sea (Port mirrored to starboard for valid comparison) 
overall instead of mainly at the bow. Relatedly, the smaller percentage reduction at the bow than at the stern can be explained by the larger denominator, since the absolute MSI reduction was similar regardless of the longitudinal location.

\subsection{Dimensionless vertical acceleration along vessel length}

The purpose of this section is to better understand how the RCS influences the MSI, though looking at vertical accelerations as a function of both position and frequency. The vertical accelerations thus contain information that is lost in RAOs and MSI since (1) while heave and pitch RAOs describe the vessel motions as functions of frequency, they only indirectly provide information about the spatial distribution of vertical accelerations (and only if the relative phase is known); (2) on the other hand, while MSI provides this spatial information, it reduces data to a single value for each location, losing information about the frequency dependence of the motions-in particular, one loses information about whether conditions at the ship's resonant frequency, or at frequency of peak human sensitivity, or indeed other frequencies, have had more influence on the outcomes.

To visualise more clearly how the active T-foil reduces MSI, dimensionless vertical accelerations are plotted along the length of the vessel at representative frequencies. The local vertical acceleration amplitude is computed by multiplying the local heave RAO by $\omega_{\mathrm{e}}^{* 2}$, where the local heave RAO is extrapolated from the heave RAOs at four different longitudinal locations. The evaluation method for the heave RAOs is described in Sect. 2.3, with the addition that the power spectra were smoothed using a window of 6000 samples to provide a representative acceleration for analysis.
The dimensionless vertical acceleration distributions at speeds of 20, 30 and 35 knots are plotted in Figs. 15, 16 and 17, respectively. Each figure is split into four subplots: low frequency; the frequency of the maximum of the MSI weighting curve; the ship's first rigid body resonance; and a representative high frequency. Low frequency, here $\sim 0.1 \mathrm{~Hz}$ or $\omega_{\mathrm{e}}^{*}=2.0$, demonstrates the hull response in long waves; $\sim 0.17 \mathrm{~Hz}$ or $\omega_{\mathrm{e}}^{*}=3.3$ is crucial for understanding the passenger comfort; the hull natural frequency, $\sim 0.23 \mathrm{~Hz}$ or $\omega_{\mathrm{e}}^{*}=4.5$, represents the largest motions of the vessel; and finally, motions are examined at a higher frequency where they are still significant, in this case $\sim 0.33 \mathrm{~Hz}$ or $\omega_{\mathrm{e}}^{*}=6.5$. It is noted that the $\omega_{\mathrm{e}}^{* 2}$ multiplier in the acceleration expression contributes to the nontrivial significance of the high frequencies relative to low in the MSI calculations, so the importance of the $\omega_{\mathrm{e}}^{*}=6.5$ should not be underestimated.

At 20 knots (Fig. 15), there was no significant reduction in local motions at any point caused by the T-foil, regardless of the encountered frequency. This agreed with previous finding in relation to RAOs and MSI, and was again expected because of the lower lift force of the T-foil and/or tabs generated at low speed.

At 30 knots (Fig. 16), the heave acceleration reduction upon activation of the T-foil can be observed quite strongly at $\omega_{\mathrm{e}}^{*}=4.5$, and to a lesser extent at $\omega_{\mathrm{e}}^{*}=3.3$. At the LCG $(\sim 40 \% \mathrm{LWL})$, about $21 \%$ reduction at $\omega_{\mathrm{e}}^{*}=3.3$ was recorded, which is consistent with the MSI reduction prediction shown in Fig. 11b. A similar reduction can also be observed at $\omega_{\mathrm{e}}^{*}=$ 4.5 , but at this frequency the T-foil activity was able to limit the heave motion throughout the whole vessel.

Figure 17 shows the heave acceleration at 35 knots. At low frequency and at $\omega_{\mathrm{e}}^{*}=3.3$ there was again very
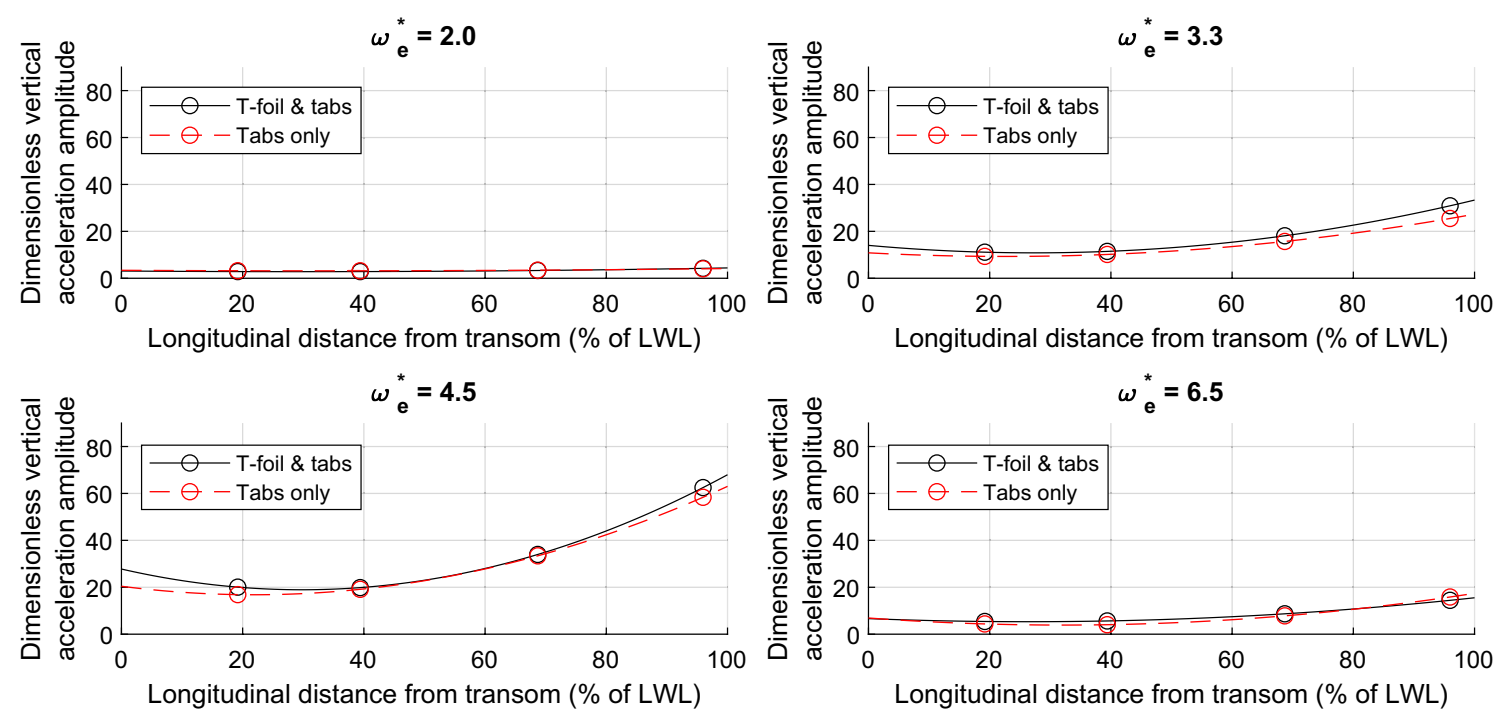

Fig. 15 Dimensionless vertical acceleration along the length of vessel at a speed of 20 knots in head seas 

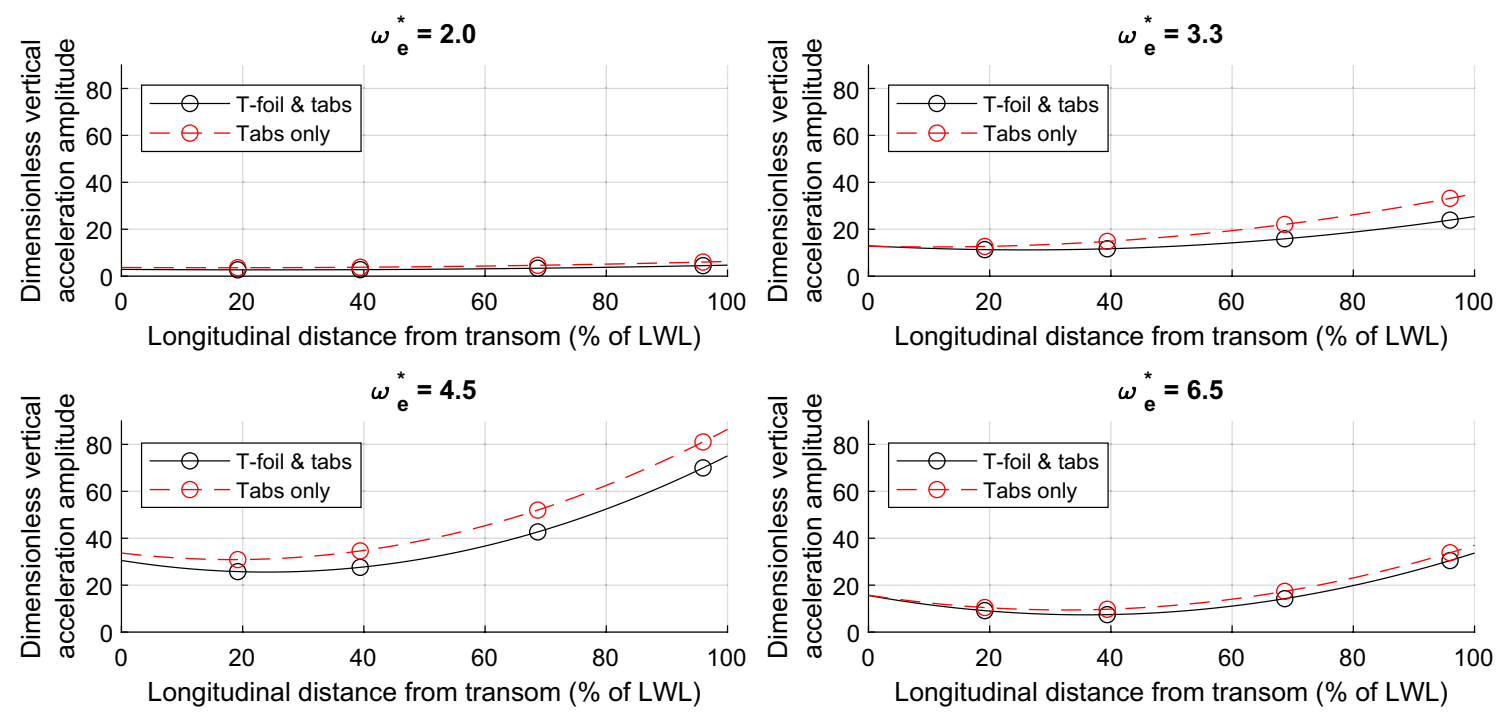

Fig. 16 Dimensionless vertical acceleration along the length of vessel at a speed of 30 knots in head seas
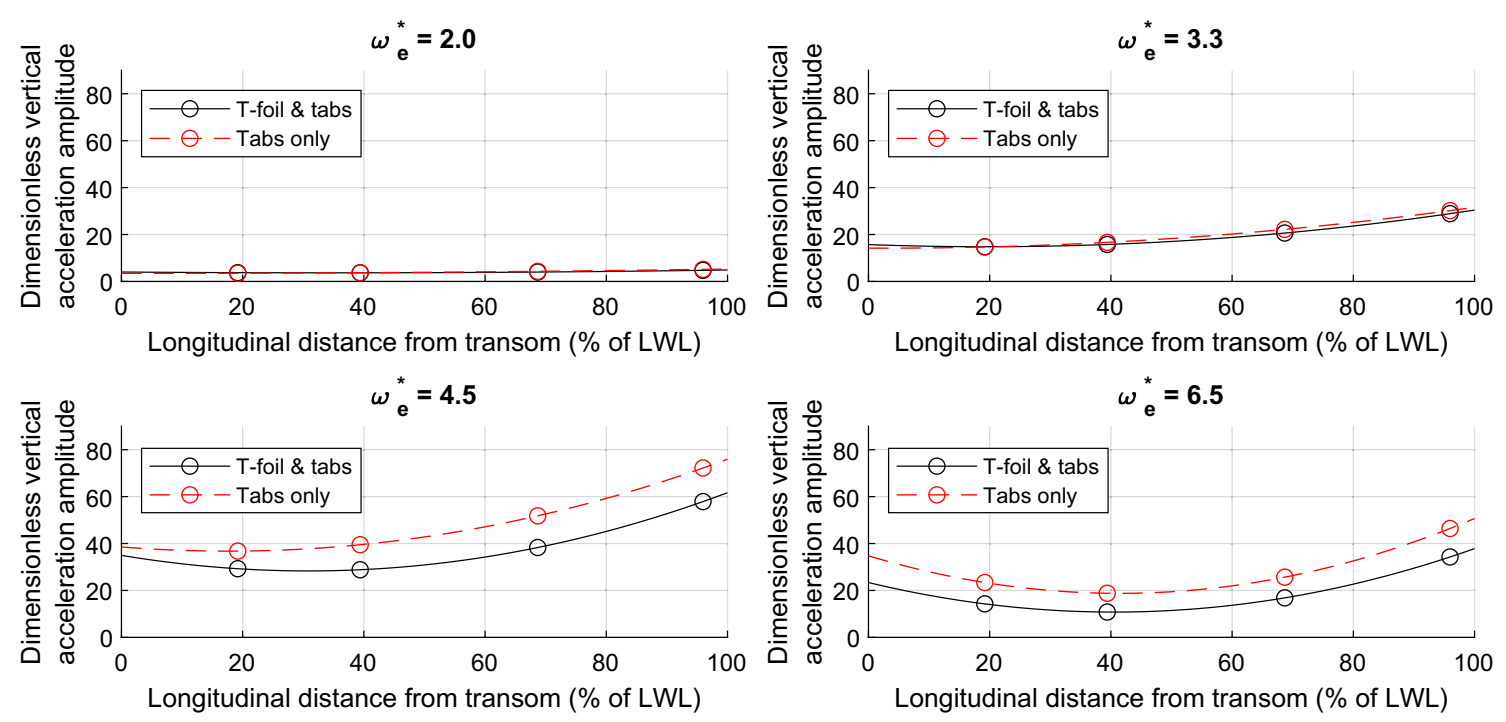

Fig. 17 Dimensionless vertical acceleration along the length of vessel at a speed of 35 knots in head seas

limited vertical acceleration reduction on deploying the T-foil. The $\omega_{\mathrm{e}}^{*}=3.3$ result was not expected, since the percentage reduction of MSI reached about $20 \%$ in Fig. 11 b. Nevertheless, it could be explained by the effective motion reduction frequency range of the T-foil $\left(4 \leq \omega_{\mathrm{e}}^{*} \leq 6\right)$ discussed earlier with reference to Fig. 9e. Moreover, consistent with the Fig. 9e results, at the two higher frequencies $\left(\omega_{\mathrm{e}}^{*}=4.5\right.$ and $\left.\omega_{\mathrm{e}}^{*}=6.5\right)$, the dimensionless vertical acceleration was again significantly reduced over the whole ship length on deployment of the active T-foil.
Amongst all cases discussed, the highest heave reduction $(\sim 35 \%)$ consistent over the whole vessel is found at 35 knots at $\omega_{\mathrm{e}}^{*}=6.5$, followed by $\omega_{\mathrm{e}}^{*}=4.5$ at the same speed $(\sim 23 \%)$. This demonstrates the ability of the active T-foil to control global vertical acceleration over the whole ship at high-speed.

Overall, the highest vertical acceleration is found at the bow, while the lowest is generally near the LCG, which agrees with the MSI distribution shown in Fig. 14a as well as the observation made by Davis [35] of MSI changes along hull. Furthermore, at $\omega_{\mathrm{e}}^{*}=2.0$, the dimensionless vertical 
accelerations remained very low regardless of the speed. The acceleration amplitude was again lower at $\omega_{\mathrm{e}}^{*}=6.5$, though still significant. At $\omega_{\mathrm{e}}^{*}=3.3$ and $\omega_{\mathrm{e}}^{*}=4.5$, the influence of T-foil deployment was a function of both vessel speed and encounter frequency - at higher velocity, the effective range of motion reduction tended to shift toward higher frequencies.

\section{Conclusions}

To investigate the contribution of deploying an active T-foil on vessel motion control and passenger comfort, sea trial records for a $98 \mathrm{~m}$ piercing-wave catamaran, HSV-2 Swift, were analysed. This study not only provide insight of fullscale WPC motion in random waves, but also demonstrate some new characteristics that have not been discussed in existing model tests and numerical analyses. The Incat Tasmania catamaran was equipped with a retractable T-foil located aft of the centre bow, and two trim tabs fitted at the stern of the two demi-hulls. Throughout the sea trials, the stern tabs were always actively used to counterbalance the pitch and roll motion in damping control, while the T-foil could be deployed or retracted. Thus, the influence of the active T-foil deployment with assistance of stern tabs was evaluated in this study.

Heave and pitch motion response amplitude operators (RAOs) were calculated and compared with previous studies and analytical predictions. The RAOs at 20-35 knots in head seas showed that, compared with active stern tabs only, the combination of T-foil and stern tabs can effectively reduce the heave peak RAO by about $23 \%$ when the forward speed was greater than 20 knots, but there was no significant decrement in pitch RAO observed with deployment of the T-foil, regardless of forward speed. Comparing the heave RAOs at 30 and 35 knots in random seas, the effective frequency range of the T-foil was noted to shift upwards from $3 \leq \omega_{\mathrm{e}}^{*} \leq 5$ to $4 \leq \omega_{\mathrm{e}}^{*} \leq 6$.

The RAO plots showed evidence that the effective RideControl System (RCS) algorithm was a combination of damping and stiffness control, which was attributed to the phase lag between the demanded control surface deflections and the actual control forces. Further investigating the phase lag, the resultant damping and stiffness ratio was estimated, along with the effect of encounter frequency and control surface type. That suggested that vessel motions might be further reduced with adjustments to the control set-up.

A linear regression was fitted to generalise the effect of T-foil deployment on 2-h motion sickness incidence (MSI). Like the RAO, a reduction of MSI in head seas due to the T-foil was only observed when the vessel was travelling faster than 20 knots. The MSI decrease was up to about $23 \%$ at 35 knots, and around $15 \%$ on average, but depended on the speed and wave height.
The influence of heading on MSI at high speed was also examined and visualised in a polar plot. In general, it was clear that the MSI was highest when the vessel encountered head seas, while the MSI was halved in bow-quartering seas. The MSI further reduced as the heading approached the stern: in beam seas and following seas, the values reduced to less than a quarter of the head seas MSI.

To better understand the environment to which passengers were exposed, MSI on the passenger deck was also assessed. The motions experienced at the centre of the stern was the lowest in the entire cabin, and further benefited by up to $14 \%$ MSI reduction with the T-foil deployment.

The dimensionless vertical acceleration along the vessel length at specific frequencies was evaluated to highlight the connection between vertical heave motion and MSI. In short, the accelerations were consistent with the heave RAO and MSI, e.g. the T-foil decreased the heave acceleration by about $20 \%$ when the vessel speed was above 20 knots. As with heave displacement, the effective frequency range of the T-foil for vertical acceleration reduction shifted to higher frequencies when the speed increased, i.e. from $3 \leq \omega_{\mathrm{e}}^{*} \leq 5$ at 30 knots to $4 \leq \omega_{\mathrm{e}}^{*} \leq 6$ at 35 knots. This shift to higher frequencies affected the ability of T-foil deployment to control hull motions and improve passenger comfort due to the system inertia.

Finally, the sea trials demonstrated fair agreement with previous towing tank studies and numerical calculations. Nevertheless, the measured dataset also showed some unique characteristics that had not previously been fully understood, such as that the resultant control was a combination of stiffness and damping modes, and the shift of the T-foil effective frequencies range and their influences.

Acknowledgements The authors thank Incat Tasmania Pty Ltd and Revolution Design Pty Ltd, especially Dr. Jason McVicar, for their support towards this research work. Naval Surface Warfare Center, Carderock Division (NSWCCD) is also acknowledged for providing access to data collected from sea trials on HSV-2 Swift. The Australian Research Council (ARC) is also gratefully acknowledged in supporting this work thru Linkage Grant LP 1701000555.

Funding Open Access funding enabled and organized by CAUL and its Member Institutions.

Open Access This article is licensed under a Creative Commons Attribution 4.0 International License, which permits use, sharing, adaptation, distribution and reproduction in any medium or format, as long as you give appropriate credit to the original author(s) and the source, provide a link to the Creative Commons licence, and indicate if changes were made. The images or other third party material in this article are included in the article's Creative Commons licence, unless indicated otherwise in a credit line to the material. If material is not included in the article's Creative Commons licence and your intended use is not permitted by statutory regulation or exceeds the permitted use, you will need to obtain permission directly from the copyright holder. To view a copy of this licence, visit http://creativecommons.org/licenses/by/4.0/. 


\section{References}

1. Eurostat (2021) Maritime freight and vessels statistics. In: Statistics explained. Eurostat [Online]. https://ec.europa.eu/eurostat/ statistics-explained/pdfscache/6652.pdf. Accessed 20 May 2021

2. Yun L, Bliault A (2012) Features of high speed catamarans. In: High performance marine vessels. Springer, Boston, p 209, ISBN 978-1-4614-0868-0 e-ISBN 978-1-4614-0869-7, https://doi.org/ 10.1007/978-1-4614-0869-7

3. Veer APVT (1998) Behaviour of catamarans in waves. Faculty of design, engineering and production, marine technology, Delft University of Technology, Netherlands

4. Fang CC, Chan HS, Incecik A (1996) Investigation of motions of catamarans in regular waves-I. Ocean Eng 23:89-105

5. Fang CC, Chan HS, Incecik A (1997) Investigation of motions of catamarans in regular waves-II. Ocean Eng 24(10):949-966

6. Tezdogan T, Incecik A, Turan O (2014) Operability assessment of high speed passenger ships based on human comfort criteria. Ocean Eng 89:32-52

7. Incat (2021) Incat official website. Incat. https://www.incat.com. au. Accessed 32021

8. Davis MR et al (2009) Slamming and whipping of wave-piercing catamarans. Presented at the hydroelasticity in marine technology international conference, Southampton, UK, 2009, 2009, refereed conference paper (Online). http://ecite.utas.edu.au/58632. Accessed 8 Dec 2021

9. Shabani B, Lavroff J, Holloway DS, Davis MR, Thomas GA (2018) The effect of centre bow and wet-deck geometry on wetdeck slamming loads and vertical bending moments of wavepiercing catamarans. Ocean Eng 169(1):401-417. https://doi.org/ 10.1016/j.oceaneng.2018.09.028

10. Lavroff J (2009) The slamming and whipping vibratory response of a hydroelastic segmented catamaran model. University of Tasmania

11. Shabani B, Lavroff J, Davis MR, Holloway DS, Thomas GA (2018) Slam loads and kinematics of wave-piercing catamarans during bow entry events in head seas. J Ship Res 62(3):134-155. https://doi.org/10.5957/JOSR.180001

12. Shabani B, Lavroff J, Davis MR, Holloway DS, Thomas GA (2019) Slam loads and pressures acting on high-speed wavepiercing catamarans in regular waves. Mar Struct 66:136-153. https://doi.org/10.1016/j.marstruc.2019.03.007

13. Shabani B, Lavroff J, Holloway DS, Davis MR, Thomas GA (2019) Wet-deck slamming loads and pressures acting on wave piercing catamarans. Int Shipbuild Prog 66(3):201-231. https:// doi.org/10.3233/ISP-180247

14. Jacobi G (2011) High-speed catamaran motion response and slamming behaviour during full scale trials. Degree of Diploma of Engineering (Naval Architecture), University of Tasmania, Australia

15. AlaviMehr J, Davis MR, Holloway DS, Lavroff J, Thomas GA (2017) Optimisation of ride control operation to reduce motions and loads of high-speed catamarans. In: Presented at the 14th international conference on fast sea transportation, Nantes, France, 2017, non refereed conference paper. [Online]. http:// ecite.utas.edu.au/121692. Accessed 31 Mar 2021

16. AlaviMehr J, Davis MR, Holloway DS, Lavroff J, Thomas GA (2019) Outcomes of recent work on the optimisation of ride control operation to reduce motions and loads of high-speed catamarans. In: Presented at the 38th international conference on ocean, offshore and Arctic Engineering (OMAE 2019), Glasgow, Scotland, 2019, conference extract [Online]. http://ecite.utas.edu.au/ 133729. Accessed 22 Feb 2021

17. Shabani B, Lavroff J, Holloway DS, Davis MR, Thomas GA (2019) The influence of the centre bow and wet-deck geometry on motions of wave-piercing catamarans. J Eng Marit Environ 232(2):474-487. https://doi.org/10.1177/1475090217753761

18. AlaviMehr J, Lavroff J, Davis MR, Holloway DS, Thomas GA (2019) An experimental investigation on slamming kinematics, impulse and energy transfer for high-speed catamarans equipped with ride control systems. Ocean Eng 178:410-422. https://doi. org/10.1016/j.oceaneng.2019.02.004

19. He W, Yang S, Xie W, Hou G (2019) Research on motion reduction of a T-foil on the wave piercing catamaran. In: Presented at the 2nd international conference on frontiers of materials synthesis and processing, 2019

20. Fang C-C, Chan H-S (2004) Investigation of seakeeping characteristics of high-speed catamarans in waves. J Mar Sci Technol $12: 7-15$

21. Incat (2021) Passenger comfort. Incat. https://www.incat.com.au/ passenger-comfort/. Accessed 32021

22. Shabani B, Holloway DS, Lavroff J, Davis MR, Thomas GA (2017) Systematic model tests on centre bow design for motion and slamming load alleviation in high speed catamarans. In: Presented at the 14th international conference on fast sea transportation, Nantes, France, 2017, 2017, non refereed conference paper [Online]. http://ecite.utas.edu.au/121691. Accessed 20 May 2021

23. Shabani B, Lavroff J, Holloway DS, Davis MR, Thomas GA (2019) Centre bow and wet-deck design for motion and load reductions in wave piercing catamarans at medium speed. Ships Offshore Struct. https://doi.org/10.1080/17445302.2019.17080 43

24. Shahraki JR, Thomas GA, Penesis I, Amin WAI, Davis MR, Davidson G (2014) Centrebow design for wave-piercing catamarans. In: Presented at the 12th international conference on fast sea transportation, Amsterdam, 2014, conference extract [Online]. http://ecite.utas.edu.au/88752

25. Incat (2021) HSV-2 Swift (Hull 61) specification. Incat. https:// www.incat.com.au/vessel-progress/current-fleet/. Accessed 2021

26. AlaviMehr J, Davis MR, Lavroff J, Holloway DS, Thomas GA (2016) Response of a high-speed wave-piercing catamaran to an active ride control system. $\mathrm{R}$ Inst Nav Archit Trans Part A Int J Marit Eng 158(A4):A325-A335. https://doi.org/10.3940/rina. ijme.2016.a4.382

27. AlaviMehr J, Lavroff J, Davis MR, Holloway DS, Thomas GA (2017) An experimental investigation of ride control algorithms for high-speed catamarans Part 1: reduction of ship motions. J Ship Res 61(1):35-49. https://doi.org/10.5957/JOSR.61.1.160041

28. Smith N (2013) Identification of ride control system parameters for a 98 metre high speed catamaran. Engineering School, University of Tasmania, Hobart

29. AlaviMehr J, Lavroff J, Davis MR, Holloway DS, Thomas GA (2017) An experimental investigation of ride control algorithms for high-speed catamarans Part 2: mitigation of wave impact loads. J Ship Res 61(2):1-13. https://doi.org/10.5957/JOSR.61.2. 160046

30. Bachman RJW, Dennis A, Powell MD (2004) HSV-2 swift seakeeping trials, 2004. Naval Surface Warfare Center Carderock Division

31. Jacobi G, Thomas G, Davis MR, Holloway DS, Davidson G, Roberts T (2012) Full-scale motions of a large high-speed catamaran: the influence of wave environment, speed and ride control system. Int J Marit Eng 154(A3):A143-A155. https://doi.org/10.3940/ rina.ijme.2012.a3.238

32. Holloway DS, Davis MR (2002) Application of two dimensional boundary element methods to ship motion predictions. In: Presented at the second international conference on fluid dynamics, Sydney, Australia, 2002, non refereed conference paper [Online]. http://ecite.utas.edu.au/24570. Accessed 18 Dec 2021 
33. Holloway DS, Davis MR (2006) Ship motion using a high Froude number time domain strip theory. J Ship Res 50(1):15-30

34. Davis MR, Holloway DS (2003) Motion and passenger discomfort on high speed catamarans in oblique seas. Int Shipbuild Prog 50(4):333-370

35. Davis MR (2020) Operation of T-Foils and Stern Tabs to Improve Passenger Comfort on High-Speed Ferries. J. Ship Res pp. 1-20,

36. O'Hanlon JF, McCauley ME (1974) Motion sickness incidence as a function of the frequency and acceleration of vertical sinusodal motion. Aerosp Med 45(4):366-369

37. McCauley ME, Royal JW, Wylie CD, O'Hanlon JF, Mackie RR (1976) Motion sickness incidence exploratory studies of habituation, pitch and roll, and the refinement of a mathematical model. Office of naval research department of the navy, California

38. Lawther A, Griffin MJ (1986) The motion of a ship at sea and the consequent motion sickness amongst passengers. Ergonomics 29(4):535-552. https://doi.org/10.1080/00140138608968289

39. Davis MR, Holloway DS (2003) Effect of sea, ride controls, hull form and spacing on motion and sickness incidence for high speed catamarans. In: Presented at the 7th international conference on fast sea transportation, Ischia (Italy), 2003, refereed conference paper. [Online]. http://ecite.utas.edu.au/26857

40. Holloway DS (2003) Davis MR (2003) Seakeeping computations of semi-SWATHs at high Froude number. Trans R Inst Naval Archit Part A Int J Marit Eng 145(A2):1-13. http://ecite.utas.edu. $\mathrm{au} / 26861$.

41. Piscopo V, Scamardella A (2015) The overall motion sickness incidence applied to catamarans. Int J Nav Archit Ocean Eng 7:655-669
42. ISO 2631-1:1997(E) Mechanical vibration and shock-evaluation of human exposure to whole-body vibration - part 1 general requirements, ISO, Switzerland, 1997

43. Thomas $\mathrm{G}$ et al (2011) Slam events of high-speed catamarans in irregular waves. J Mar Sci Technol 16(1):8-21. https://doi.org/10. 1007/s00773-010-0105-y

44. Brady TF, Bachman RJ, Donnelly MJ, Griggs DB (2004) HSV-2 swift instrumentation and technical trials plan. Naval Surface Warfare Center

45. Co T-S, Wave height meter, TSK, Kanagawa

46. Welch PD (1967) The use of fast fourier transform for the estimation of power spectra: a method based on time averaging over short, modified periodograms. IEEE Trans Audio Electroacoust 15(2):70-73

47. Harris FJ (1978) On the use of windows for harmonic analysis with the discrete Fourier transform. IEEE 66(1):51-83

48. EMODnet (2021) Bathymetry. European Union. https://portal. emodnet-bathymetry.eu/. Accessed Apr 2021

49. MIT, Water waves. Marine hydrodynamics. [Online]. http://web. mit.edu/13.021/demos/lectures/lecture19.pdf. Accessed 1 Apr 2021

50. Salvesen N, Tuck EO, Faltinsen O (1970) Ship motions and sea loads. In: The society of naval architects and marine engineers, New York, 1970: the society of naval architects and marine engineers

Publisher's Note Springer Nature remains neutral with regard to jurisdictional claims in published maps and institutional affiliations. 